\title{
Social and Industrial Aspects of Scientific Research*
}

T $\mathrm{T}$ is difficult to imagine a document which better 1 illustrates alike those social aspects of scientific research to which attention has been repeatedly directed in recent months, at the British Association meetings or elsewhere, and the way in which the direction of scientific research is itself determined by the needs of the community, than the nineteenth annual report of the Department of Scientific and Industrial Research which was issued on February 2. This report covers the period October 1, 1933, to September 30, 1934, and contains the brief report of the Privy Council Committee, signed by Mr. Stanley Baldwin, the longer report of the Advisory Council over Lord Rutherford's signature, and summaries of the work of the National Physical Laboratory, the Chemical Research Laboratory, the various research associations and research boards. Certain of the latter issue their own independent reports, but no one document issued by the Department gives such a comprehensive and lucid account of the way in which the Department of Scientific and Industrial Research serves our national life, whether in departments of State, industry or the social needs of a civilised community.

The expenditure of the Department during the year ending March 31 , 1934, was $\mathfrak{£ 6 6 4 , 4 8 2}$ gross, or $£ 476,897$ nct, as compared with $£ 451,987$ net in 1932-33. Receipts decreased, however, from

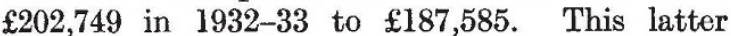
sum includes $£ 59,774$ in fees for paid work for industry ; $£ 10,209$ representing contributions from industry for co-operative research; and $£ 99,705$ from other Government funds, including a payment of

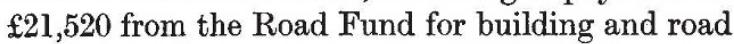
research and a grant-in-aid of $£ 30,000$ from the Empire Marketing Board for food investigation. Net expenditure on the National Physical Laboratory was $£ 118,687$; on the Chemical Research Laboratory, $£ 22,164$; building and road research,

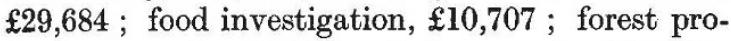
ducts research, $£ 33,911$; fuel research, $£ 80,423$; and water pollution research, $£ 5,453$. The Geological Survey and Museum received $\mathfrak{£ 6 3 , 4 2 6}$ and research associations a total of $£ 58,992$.

Particular stress is laid in the report of the Advisory Council upon the efforts made to improve the position of the research associations, as regards both obtaining greater financial support from industry and also securing the greater financial stability which is essential if long-range researches are to be undertaken and reasonable prospects of a career offered to the scientific staff. This appeal

* Department of Scientiflc and Industrial Research. Report for the Year 1933-34. (Cmd. 4787.) Pp. iv +192. (London: H.M. Stationery Office, 1935.) 38. net. for further support from industry is not, however, based solely on the prospects of future benefits. It rests equally on the results already achieved, and stress is once more laid on these other ways in which science can assist industry by the applica. tion of existing knowledge and by the extension of the scientific method and outlook.

An encouraging sign of the growth of this spirit in industry is seen in the expansion of those researches undertaken by the Department with the financial co-operation of industry. As an example of such arrangements during the year may be mentioned the research on such questions as the effect of waves on resistance and pitching of ships and their propulsion, the effect of wind resistance, the behaviour of rudders and the improvement of propellers, which are carried out in the William Froude laboratory of the National Physical Laboratory. This work, which is of fundamental importance in the design of new ships, is financed as to one half by industrial subscriptions.

Other examples of such co-operative research are found in the investigations, also at the National Physical Laboratory, bearing on the practical development of steels for use at high temperatures, as in the turbine or in chemical engineering, investigations at the Building Research Station covering the safety factors of steel-work, the discovery of British sources of materials for increasing the resistance of concretes and mortars to chemical attack, the effect of sea-water on concrete, problems of driving concrete piles, welding in steel structures, and the continuous study of heating and ventilating problems throughout the year in a 'controlled weather' house which is now being erected through the financial co-operation of industry secured through the Institution of Heating and Ventilating Engineers.

The bearing of this co-operative work at the Building Research Station on the housing question needs no emphasis. It is, however, worth noting that the introduction of new materials and the displacement of obsolete regulations offer most hopeful lines of radical development in the building industry, and both alike depend on the continuous application of scientific research. The survey, conducted by the Building Research Station and the Fire Offices Committee of the fire insurance offices, of the problems of testing building materials for their resistance to fire, is overcoming difficulties in the way of provision for fire-testing stations where large-scale experiments can be conducted.

Building research in fact figures prominently in the report. Proposals made by the Advisory Council are concerned with an expansion of the 
activities of the Station whereby the results of research and investigation would become available at an earlier date and also with the special problems involved in the construction of flats. These include investigations on fire risks designed to test whether regulations in Great Britain are too restrictive or not, and others relating to the transmission of sound through the structural elements or through floors and partitions.

From housing questions it is an easy transition to problems bearing on food supply, and here the work of the Department affords a striking example of scientific co-operation with the Dominions overseas. Even the brief summary contained in the Advisory Council's report indicates our immense debt in this field to Sir William Hardy, and the work of the Food Investigation Board is steadily growing in importance. At the Covent Garden laboratory there is a full-time officer, experienced in the examination of experimental consignments of fruit and vegetables sent to Great Britain, whose services are also available for Dominion and Colonial Governments. A definite advance has been recorded during the year in the application of gas-storage to shipments of chilled beef from Australia and New Zealand and a modified method of stowage has been developed which promises to be more effective and economical.

Investigations in this field range over almost every type of foodstuff. A storage atmosphere has been worked out, for example, in which the characteristic flavour of Cox's Orange Pippin apples can be retained during six months' storage. Experiments at a Wiltshire factory have shown that rapidly growing pigs are more suitable for bacon production than slowly growing pigs. With lighter salting supplemented by cold storage, a method of cure has been evolved which produces salted herrings more delicate in flavour and more suited to the modern palate than those previously available. Problems of the herring industry have also been considered, and the discovery that herrings, frozen in brine at $-20^{\circ} \mathrm{C}$., make good kippers after four months' storage at that temperature, which is now being tested on a semicommercial scale, may enable supplies to be carried over from periods of glut to the times of shortage experienced particularly in winter.

Besides the Food Investigation Board, several of the research associations are concerned with investigations on foodstuffs. The Research Association of British Flour Millers is studying the reasons for one flour giving better bread and dough than another, and developing methods of measuring the physical properties of dough. The Research Association for the Cocoa, Chocolate, Sugar Confectionery and Jam Trades has indicated methods for preventing boiled sweets being re- duced to a sticky mass by the absorption of moisture and has also suggested modifications in the composition of such sweets to prevent coalescence under the influence of heat.

Turning from food to clothing, we are still within the field in which the activities of the Department touch the home. The British Boot, Shoe and Allied Trades Research Association has done much to improve footwear service by providing knowledge which makes shoes more hygienic and comfortable, while the Leather Manufacturers Research Association has given a good deal of attention to the prevention of mould growth on leather. The Wool Industries Research Association's new process for unshrinkable wool, yarns and fabrics is being exploited under mill conditions, and materials should be available for the public early in this year. New motor fabrics from wool and rubber latex are also being introduced to the public. The Linen Industry Research Association has investigated the behaviour of linen under repeated launderings, and other research in this field is undertaken by the Launderers' Research Association.

Leaving the home we come naturally to transport, where the Road Research Station is responsible for fundamental work on road construction, which has a vital bearing on safety on the roads ; skidding problems and lighting problems are both being investigated.

Space permits not even the briefest reference to many other ways in which the work of the Department of Scientific and Industrial Research is affecting almost all our public services-power, water, lighting, gas, fuel-and steadily raising their efficiency. Mention should, however, be made of the work of the Forest Products Research Labora. tory on Empire timbers, of investigations on the detection of toxic gases and the production of cheap and efficient respirators for use in industries where dust is a menace to health, investigations on cylinder wear of internal combustion enginesprobably the most important cause of deterioration in the engines of motor-cars-radio research on the propagation of waves and long-distance transmission, dental investigations, illumination research, investigations on lubricants and on atmospheric pollution, if only to illustrate the immense range of activities of this one Department. Nor should it be forgotten that, in the various institutions aided by the Department, new instruments and methods are continuously being developed by which the control of existing processes or the solution of urgent problems is being achieved. The interpretation and exposition of the record of work contained within the covers of this report is a task to which every scientific worker might well address himself. 